\title{
The Influences of Producing A Story on Lifetime Expenditures by Integrating Knowledge and Software on Students
}

\author{
Ting-Sheng Weng* \\ Business Administration Department, National Chiayi University, No. 580 Xinmin Road, Chiayi, Taiwan R.O.C. \\ *Corresponding author. Tel.: +886-5-2732835; email: politeweng@mail.ncyu.edu.tw \\ Manuscript submitted August 6, 2018; accepted September 13, 2018. \\ doi: $10.17706 /$ jcp.13.11.1235-1245
}

\begin{abstract}
Multimedia teaching materials and contents are now included in classroom teaching, bringing about joyful reading with images that stimulate students' interest in learning. This study utilized the applications of integration software to produce a simulation-based story on expenditures that span an individual's lifetime, covering infancy, childhood, adolescence, youth, middle-aged, and elderly. After participating in the course, producing the creative story in person, and feeding back their ideas on expenditure and wealth management, students were prompted to plan their future life. Hands-on courses can thus be advocated to help promote the interdisciplinary and integrated education of STDAM (science, technology, digital, art, maths) and to cultivate talents who can integrate theories and practices. Strategies such as theory-oriented design and exploration are incorporated in the process of hands-on practice so as to cultivate students' ability to integrate knowledge of STDAM with software.
\end{abstract}

Key words: STDAM, career planning, education on wealth management, applications of integration software, multimedia, creative comics textbook.

\section{Introduction}

Career planning is the most indispensable issue in an individual's lifetime. [1] argued that, one's attitude towards money is affected by his/her personal traits, education, and social status, and such influences are permanent [2]. [3] asserted that, one should plan his/her career as far as possible, consider his/her intelligence, aptitude, value, as well as the pros and cons, make appropriate arrangements, and strive to gain a position well suited to their place, rather than being like a chess piece in the wrong position. By realizing career planning, we can know ourselves, master our lives, make dreams come true, and effectively exert the value and meaning of life. [4] assumed that, career planning requires careful consideration and covers the entire life, including important areas, such as work, study, interpersonal relationships, and leisure. This process requires people to actively implement their plans in society. Therefore, this study deems that, career planning helps one discover himself/herself, measure their current income and expenditures, identify favorable personality traits, conduct self-analysis and assessment, correct and adjust their current abilities, and apply resources to future career planning.

Storytelling is the oldest influential tool in human history, and the most convincing communication skill [5]. A good story can touch one's heart and influence people's interpretation of things. Only by producing meaning for someone can facts influence the person. The ability to tell stories is also one of the most 
important skill for leaders in the 21st century [6]. A story is easy to remember, spread, and empathize with, as it is close to human nature, and full of emotion and vitality, thus, it can trigger people to think and arouse their feelings [7]. One of the most important skills in marketing is to create and tell stories. Multimedia applications can be leveraged to turn stories into case study. You can also digitally market stories to impress readers, which is helpful to educate students.

\section{Research Motives}

STEM (science, technology, engineering, and maths) is a teaching method that is gradually emerging in the field of education. This method emphasizing scientific education focuses on figuring out solutions to real problems. All materials needed, including theoretical knowledge, experimental materials, and resources, must be handled by students by themselves. Such practice stimulates students' thinking and creativity [8], [9].

Based on STEM, this study developed the concept of STDAM (science, technology, digital, art, and maths) so as to adapt to the integration of digital software and teaching materials and to modify the concept to be applicable to courses for students majoring in commerce. This educational concept can be applied to wealth management courses in business management education. Through this method, this study should inspire the design of more new teaching models for business management education.

The content design of a textbook from the cognitive perspective shall focus on developing students' thinking skills [10]. Different forms of textbooks can affect students' learning and perception, especially cognition [11]. The difference between comics as a reading medium and general textbooks lies in that comic contents are mainly images which can be exaggerated, simplified, and vivid. [12] thought that comics are easier to read than a textbook, and have four propagation characteristics in the popular media market: (1) entertainment effect; (2) formation of topics; (3) imagination of reading; and (4) market-oriented production.

Multimedia teaching materials can present contents in a more convenient and diversified manner, bring fun into students' learning, and improve students' willingness and motivation to read [13]. This study produced a comic featuring the stages of a lifetime as a teaching material, and students can refer to the comic to reflect on each stage of their life, which can render education more meaningful. By teaching with comics, teachers can effectively improve students' creativity. When exposed to a broad imagination space, students can discover the value of comics for learning and construct their own thinking model [14], [15]; for students, education regarding lifetime expenditures is significant. Through the comic of "Expenditures in a Lifetime", this study hopes to give full play to the roles of teaching and learning, and expose students to more diversified ways of thinking. Via teaching materials closely related to life, learners can be aroused to recall the past, to think about the present, and to plan for the future, including graduation, work, marriage, retirement, and even death.

This study believes that it is vital to cultivate talents who can integrate theory and practice, thus, it is necessary to stress hands-on courses and integrate practical skills to theory-oriented courses.

\section{Research Purposes}

Stories regarding the "expenditures of a lifetime" are seldom adopted for teaching. In this study, first, the teacher presented his own comic on the expenditures of his lifetime, covering infancy, childhood, adolescence, youth, middle aged, and elderly, in order to guide students to review their expenditures in the period from infancy to the present, and think about possible and necessary expenditures in the future. With multimedia software, students then produced their own comics of their "lifetime expenditures".

The concept of STDAM derived from this study will be applied to the course. This study developed a 
teaching model in which students could practice knowledge in wealth management, cultivate their ability to apply knowledge on STDAM, and to think about their status and expenditures in the future, including the phases of work, marriage, middle age, and old age.

\section{Literature Review}

\subsection{Application of Integration Software}

We live in a world dominated by science and technology; moreover, science and technology are the critical factors that indicate the competitiveness of a country. [16] mentioned that, as students' interest in engineering falls, the demand for talents engaged in industries related to science and engineering will exceed the supply. The US education community also hopes to enhance students' knowledge of STEM (Science, Technology, Engineering, and Mathematics), in order to adapt to the demands of the 21st century, including problem solving, self-management, self-development, systematic thinking, interaction, and communication [17], [18]. Ref. [19] expressed that, the promotion of interdisciplinary and integrated education of STEM can cultivate talents who can integrate theory and practice. Moreover, the incorporation of various strategies, such as theory-oriented design and exploration, into hands-on experience can develop students' ability to integrate STEM knowledge with practice.

Regarding research on the application of multimedia teaching materials, [20] thought that, in order to make students have good learning outcomes via multimedia applications, teachers shall emphasize intrinsic factors and support innovation, such as original imagination, conceive imagination, conversion imagination, originality, and practicality, as well as external factors, such as classes and courses. These factors help students learn the application of multimedia to interdisciplinary courses.

This study applied MomentCam App, XnView, and PowerPoint 2016 to produce its own original teaching materials. The teacher demonstrated the steps to produce the comic, and guided students to use the software and plan their future life.

\subsection{Career Planning and Wealth Management}

Career planning, or career development, refers to the extent to which an individual can reach from exploration to recession during career development, or the status of their preparations in the face of development tasks [21]. [22] divided career planning in two parts, namely, career planning and career strategy. Career planning means when an individual determines his/her career goals, understands his/her strengths and weaknesses, the degree of clarifying and planning career goals, and the extent of self-understanding. Career strategy refers to the methods and strategies adopted to achieve goals.

This study argues that the purpose of career planning is more than seeking a job. More importantly, it is to understand yourself, develop your potential, and realize yourself. Hence, we must start from understanding ourselves, and then, develop career goals and plans that suit us. Later, we turn these goals and plans into specific measures and steps to achieve them one by one. As money is inseparable in this process, wealth management must be planned to facilitate the achievement of goals.

\subsection{The Importance of Wealth Management to A Person's Life}

Wealth management can improve the quality of life of an individual or family and facilitate the realization of goals at all stages of life [23]. The ultimate goal of wealth management is to achieve financial balance, appropriately allocate money, and produce the best benefits. In other words, unnecessary expenses are saved, while quality of life is maintained [24].

Ref. [25], [26] asserted that money has different meanings for everyone. It is important to hold a positive attitude towards money and make a prudent budget. Thus, this study assumes that, education on wealth management can also improve students' mathematics abilities. Such education helps guide students to 
spend money effectively, controls money and desire, improves their social environment, and has positive impact on social values.

[27] pointed out that, financial literacy refers to the effective use of knowledge and skills of wealth management to manage one's finance and the realization of financial health in a lifetime. Students' financial literacy is related to their learning of mathematics. Higher financial literacy means better performance in mathematics. Wealth management is a vital topic in one's life, which is easily ignored. From a young age, one needs to learn wealth management, actively develop correct thinking of wealth management, lay a foundation for wealth management, and develop good habits of wealth management, such as regular bookkeeping, saving, and depositing pocket money into a moneybox. The concept of wealth management is beneficial throughout one's life. Therefore, college students about to enter society require proper wealth management concepts to help realize their dreams. Students are expected to learn how to manage their wealth and reserve funds for their dreams. In the meantime, by saving appropriately, they can better prepare for the future and achieve their goals earlier.

This study promotes the interdisciplinary and integrated education of STDAM (Science, Technology, Digital, Art, Mathematics), and cultivates students' abilities to integrate theory with practice. Furthermore, it incorporates various strategies, such as theory-oriented design and exploration into hands-on experience to cultivate students' ability to integrate STDAM knowledge with practice and software, the concept of wealth management, teamwork, and self-planning and -management.

\section{Comic on the Producer's Expenditures in A Lifetime}

This study takes college students attending an information management course as its subjects, and probes into the expenditures of a lifetime and multimedia. Through IT and the concepts of planning and management, this study creates interdisciplinary course modules, develops teaching strategies based on the Theory of Scaffolding, and combines planning and management, wealth management, IT, and software. This study guides students to understand comics, and arouses their enthusiasm to make changes, plan their lives, and manage their wealth and deposits. Students used multimedia design technologies, including digital technology, cultivation of comic character aesthetics and humanistic quality, and practical production skills. The research questions of this study were to introduce planning and management to the learning of multimedia technologies, cultivate students' ability to integrate STDAM knowledge and software, and explore the influences on students' learning outcomes.

This study introduced software to create the comic for 4 weeks, at 3 hours per week, and provided examples of software applications for students' reference.

Story telling is the oldest influential tool and the most convincing communication skill in human history. Most of the subjects were from the School of Management. In terms of cultivation of future entrepreneurs, one of the most important skills is to create and tell stories.

The students were asked how much they would spend in their lifetime. After calculation, most students' answers were over NTD30 million, which is surprising. Therefore, in order to make students pay attention to planning and management, it is necessary to make them stress wealth management first.

This study utilized apps and PPT to produce teaching materials on the expenditures of a lifetime.

Steps to produce a reality-based comic: First, the MomentCam App was adopted to produce face images at different phases, including infancy, childhood, adolescence, youth, middle-aged, elderly: for example, a chubby and cute face with a pacifier at infancy (Fig. 1), a playing child (Fig. 2), a primary school student holding a pen to learn writing and reading (Fig. 3), a middle school student studying hard (Fig. 4), a high school student playing video games with his friends (Fig. 5), an undergraduate pursing dreams and falling in love (Fig. 6), a young man busy at work (Fig. 7), a middle-aged, mature man with a beard busy at social 
interaction (Fig. 8), and a fat old man enjoying his later life (Fig. 9). Eyes, eyebrows, hairstyle, and facial expressions were designed, respectively.

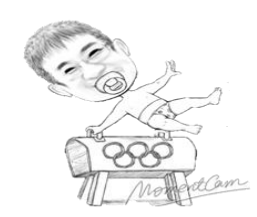

Fig. 1. The comic character at infancy.

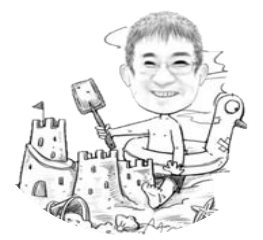

Fig. 2. The comic character at childhood.

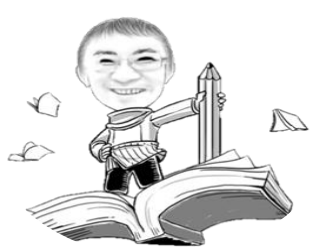

Fig. 3. The comic character at adolescence.

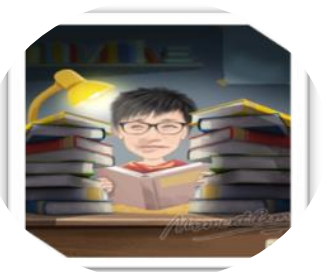

Fig. 4. The comic character in junior middle school.

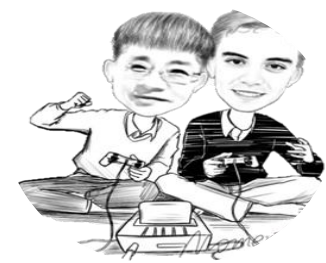

Fig. 5. The comic character in senior middle school.

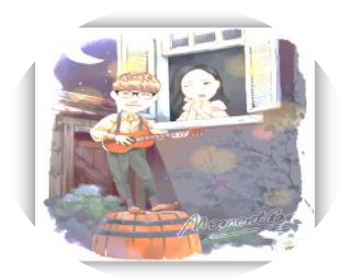

Fig. 6. The comic character at university. 


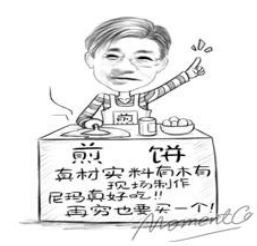

Fig. 7. The comic character in youth.

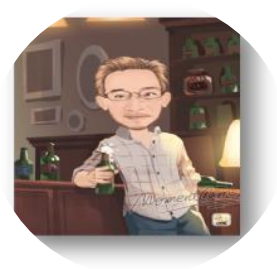

Fig. 8. The comic character in the middle-age period.

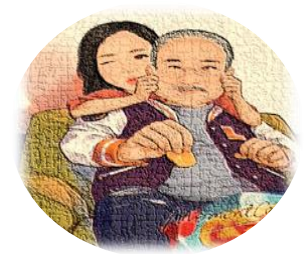

Fig. 9. The comic character in old age.

PPT was used to remove the backgrounds of pictures, add animation effects, and insert new backgrounds; the above images were cut from PPT.

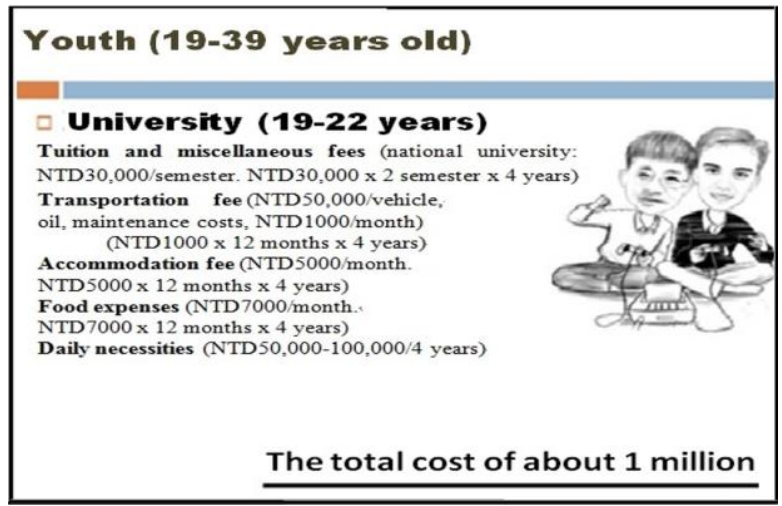

Fig. 10. Estimated expenditures at university.

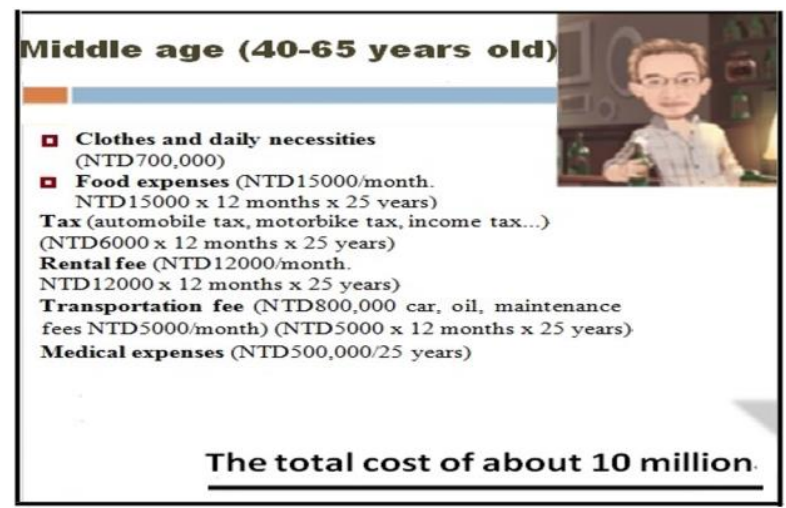

Fig. 11. Estimated expenditures during the middle-age period. 
During wealth management and planning, one must always face necessary expenditures and reality. The estimated expenditures of each phase are described, as follows: At infancy, expenditures include baby products, clothing, babysitter fees, diapers, child-care fees, medical expenses, education, and other expenses, summing up to NTD 1 million. During childhood, from 7 to 12 years old, tuition and miscellaneous fees, food expenses, security expenses, music and art training fees, and daily necessities, for a total NTD1.3 million. During adolescence, from 13 to 18 years old, expenditures including middle and high school cram school expenses are estimated to be NTD1.7million. During youth, from 19 to 22 years old, expenditures include university, which sum up to NTD1 million (according to tuition and the miscellaneous fees of a public university) (Fig. 10). From 23 to 39 years old, although one starts to work and can save money, he/she has to pay for marriage, tax, rent, and child rearing, which sum up to NTD10 million. During the middle-age period, from 40 to 65 years old (Fig. 11), the expenditures are estimated to be NTD10 million. During old age, from 65 years to death, the expenditures are estimated to be NTD 8 million. This study took the expenditures of youth in Fig. 10 and middle-age in Fig. 11 for instance.

Therefore, this study educated students to learn the basic knowledge of wealth management from childhood, including saving and consumption. Childhood to adolescence, from 11 to 18 years old: Learn to grasp and gradually develop the good habits of wealth management. Youth from 19 to 39 years old: Learn to be financially independent, reduce the burden on parents, and consider reality issues besides consumption, savings, and giving, such as: buying a car, getting married and raising children, and investing in children's education. Middle-aged from 40 to 59 years old: Continue to invest in children's education, save $12-30 \%$ of income as pension investment, and plan wealth management after retirement. Old age after 60 years old: Create a retirement budget account, achieve goals on time, and plan wealth to enjoy old age in peace.

For the last step where students were asked to provide feedback, presently in the field of business education, there is no teaching mode integrating STEM. This study is a first attempt to do so. Hence, it adopted an open way of feedback so as to collect all information from the students as much as possible. There were no limitations on the contents of feedback. Most of the feedback was students' first impressions and feelings.

\section{Experimental Process}

This study considered 55 students of one class at the School of Business Management in a university in southern Taiwan as its subjects. The experiment lasted two weeks. The theme of the course was wealth management. The experimental process is described as follows.

(1)The teacher assigned learning tasks. The final learning results must be presented via "animation" (1 hr).

(2)The students were asked to review their wealth management methods ( 2 days).

(3)The students designed their scripts to fully describe their wealth management methods and expenditure habits (3 days).

(4)The students looked for software to design the comic (2 days).

(5)The students designed the comic (1 week).

(6)The students completed and displayed the work.

(7)The students were asked to provide feedback on the entire teaching experiment.

\section{Results}

This study required each student to write an article of at least 2,000 words on their course experience, and selected three articles to explain the results. Students A and C are female, while Student B and D are 
male.

\section{Student A's experience:}

"Everyone has a life plan. The comic used by my teacher to assist his teaching in the classroom aroused my curiosity to know how much money people spend in their lives. Our team calculated the expenditures of a lifetime from infancy to old age, and the expenditures of all phases summed up to nearly NTD32.65 million. We referred to our teacher's comic and integrated STDAM knowledge in our work. We learned how to integrate science, technology, digital, art, mathematics, and management to make our learning more interesting. We combined the knowledge to our comic under the professional guidance of our teacher. Each time we submitted our assignment, our teacher would discuss it with us face to face and help us. Moreover, through the networking teaching platform, our teacher gave us suggestions, and we modified our work accordingly. Our teacher wanted us to integrate literacy of (science, technology, digital, art, maths) in our work, and helped us identify more suitable production methods. By watching the comic/animation of our teacher, we learned how to make our work more interesting and vivid, as we could adopt diversified ways to present images and discuss together how to complete the work. Students in the same group discussed and worked together to complete a comic on the expenditures of a lifetime. We also produced images, inserted texts into PPT slides, and applied the animation effects in PPT slides to design our work. In the case of difficulties in task assignment, we would help each other, apply what we could, and learn from and encourage each other. The work allowed us to know how much we would spend in a lifetime. Before starting this work, I had never thought about this question. After this experience, I know how much I would spend in a lifetime; however, we will probably spend more than our estimation."

"In terms of image production, we learned how to use MomentCam App to produce interesting and vivid images. Overall speaking, we learned how to apply PPT and MomentCam to our assignment, and last, but not least, I learned how to communicate with and learn from my teammates to improve myself."

\section{Student B's experience:}

"I think this topic is very people-oriented, as we all die in the end. It is good to study ourselves. Through this assignment, we learned how much money one may spend in a lifetime, and we need to save money rather than dipping into our purses. The expenditures calculated in our assignment do not include entertainment expenses."

"We referred to the comic made our teacher and used MomentCam to produce our own comic. We hoped that the characters we designed would be comic. We carefully designed each image from infancy to old age, listed all the expenditures, and then, discussed together. Furthermore, we referred to others' opinions on the Internet to sum up all the expenditures."

"One keeps learning and working in a lifetime in order to live a better life, and better material life is supported by our work. We work hard to promote the advance of society. This hands-on experience offered me a good opportunity to learn comic production skills."

"Life is like a play. Every one is the leading actor in his/her own play and supporting actor in others' plays. Leading and supporting actors are on the same stage."

"After completing this assignment, I feel that life is like a mirror. We see truth, kindness, beauty, and ugliness from the mirror. What are we after? Life is like a sewing machine, and we must process the materials we use."

"With software, I produced the images of birth. A baby is full of curiosity, everything is unknown to it, and he needs to keep exploring and learning."

"During my teenage years, I no longer staggered. My parents started to let me make decisions, and I learned to be independent, which helped reduce the burden on my parents so that they could have more time to 
rest and did not need to worry about me. Recalling the past, I deeply feel that I shall not be addicted to playing around. Instead, I need to study hard and cherish every moment."

"During my youth, I left my parents to live independently. I could no longer lead an easy life with everything provided. I left the "air-conditioner in the greenhouse" and needed to face wind and rain by myself. In the face of all difficulties, I tell myself that where I fall, is where to stand up! " "Looking into the future, I may have my own family and career in my middle-age period. I will work diligently so that my children can live a happy life. I will no longer have the naive smile and care-free pleasure of childhood. What I have will only be the backpack of life, containing troubles, burdens, and disappointments. I may get overwhelmed gradually."

"In my old age, I may sit in a cane chair, look at children playing, recall my own childhood, and cannot help smiling. I used to cry often, laugh a lot, fight, be disobedient, and did not talk much. How time flies. I will become a silver-haired old man. I will no longer be full of energy."

"One needs to go through thick and thin in a lifetime. Can I get through it? It is not right if one only thinks about "sweetness" rather than other flavors. With a brave heart, we must get through the bitter tastes."

"Therefore, we need to savor every bite of life slowly, as everyone's life is different."

\section{Student C's experience:}

"When learning the software with my classmates, I realized that a man needs to be brave in life. Some just exist in the world, rather than live a true life. We need to feel and appreciate everything around us with an open heart, endeavor to become unique, slowly experience our life, inject new meanings, and dedicate ourselves to helping others."

"My parents dedicate themselves to me, and offer me capital to make achievements. Their value and desire extend in my body. I cannot change the starting or end points of my life, but I will strive to enrich my life!"

"From the above experience, we can see that, while applying the software to produce the comic, students discussed with their teacher and classmates via the community and modified their work according to their teacher's opinions. We learned to divide tasks among teammates, cooperate, assume well matched management function, and improved our skills."

\section{Students D's experience:}

"Finishing the work, I was very excited and mentioned that although I was not overly sensitive to money issues, I did not realize that I spent so much of the money."

This study holds that students learned more than the application of software skills; they learned how to produce a creative comic. When they realized that they would spend a considerable amount of money in their lives, they were stimulated to manage their wealth, and think about how to save money for maximum benefits. Additionally, some students asked about the purpose, meaning, and value of life; some mentioned that, as life is short and bitter, one needs to be persistent, and should recall their limited lifespan and the sunshine in life. We need to cherish what we have, face life positively, devote ourselves to helping others, and realize our own value.

The above is the feedback of some participants in this study. Through this teaching method, the main changes perceived by the students are as follows.

(1) Learned to plan, execute, and look for resources.

(2) Practiced team communication skills.

(3) Asked questions and tried to propose a solution.

This study required the students to present their results via "comic". The students must consider how to make the comic and obtain the necessary resources. When the resources were not available, they learned how to modify their work and achieve the goal. This process stimulated the students' thinking and creativity. The comics produced in this study are based on reality, which responds to [5], who mentioned that a good story can touch the hearts of students and influence their interpretation of things. Students 
were stimulated to stress the significance of future planning. From the article on the experience of each student, it can be seen that the topic promoted by this study, as well as the hands-on experience, had a deep influence on the students.

\section{Conclusions}

This study introduced STDAM to the hands-on experience of students. After producing the comic, students were able to obviously and more deeply perceive the significance of the "application of integration software", "education on wealth management", "wealth management", "career planning", "introduction of a comic to classroom teaching", "artistic and creative design of pictures", and "meaning of life". From the experiences written by the students, we can see that the purpose of cultivating digital skills was realized. Moreover, the students gained a deeper understanding of the knowledge and skills related to career planning and wealth management, and thus, cultivated better abilities in their interpretations of life and problem solving.

This study instructed students to integrate multimedia software with their learned knowledge. In four weeks, students used apps and PPT to make a comic of their own stories. Stories leave a broad space of imagination and awakens people's heart, and companies can establish a good brand image by telling their stories in the future.

\section{Suggestions}

It is suggested that future researches can produce stories of enterprises to impress consumers, achieve emotional marketing, and create good brand image and brand reputation.

\section{Acknowledgement}

This study was financially supported by the Ministry of Science and Technology under grant no. MOST 106-2511-S-415-013-MY2y.

The author appreciates the comments of the review committees, including Yi-hsin Chi, Shih-hsuan Huang, and Hsueh-fen Hung.

\section{References}

[1] Furnham, A. (1984). Many sides of the coin: The psychology of money usage. Personality and Individual Differences, 5, 501-509.

[2] Alvin. (2014). Earn More Money after Work. Taipei: Sun Color Culture.

[3] Keefe, B. (2010). The Perception of STEM: Analysis, Issues, and Future Directions, Survey. Entertainment and Media Communication Institute.

[4] Kirkcaldy, B., \& Furnham, A. (1993). Predictors of beliefs about money. Psychological Reports, 73, 1079-1082.

[5] Super, D. E. (1957). The Psychology of Careers. New York: Harper \& Row.

[6] Baek, E., \& Monaghan, J. (2013). Journey to textbook affordability: An investigation of students' use of eTextbooks at multiple campuses. International Review of Research in Open and Distance Learning, 14(3), $1-26$.

[7] Hung, F. Y. (2000). Career Planning. Taipei: Yang-Chih Book.

[8] Bybee, R. W. (2010). Advancing STEM education: A 2020 vision. Technology and Engineering Teacher, 70(1), 30-35.

[9] Moore, T. J., Stohlmann, M. S., Wang, H. H., Tank, K. M., Glancy, A. W., \& Roehrig, G. H. (2014). Implementation and integration of engineering in K-12 STEM education. Engineering in Pre-college 
Settings: Synthesizing Research, Policy, and Practices, Purdue University Press.

[10] Risner, G. P., Nicholson, J. I., \& Webb, B. (2000). Cognitive levels of questioning demonstrated by new social studies textbooks. Proceedings of the Annual Conference of the Mid-South Educational Research Association, Bowling Green.

[11] Li, H. C. (1994). Financial Management for the Elderly. Taipei: World Books.

[12] Hsiao, H. W. (2002). Study on Comics: Study on Communication of Ideas. Taipei: Wunan Book.

[13] Chang, H. Y. (2008). Leaders, Leverage Your Storytelling Ability. Taipei: Elegant Books.

[14] Peng, H. Y. (2009). Integration of comic with composition to facilitate students to write. Journal of Basic Education, 3, 28-29.

[15] Hale. (2012). Power of Stories. Taipei: Yishiang Culture.

[16] Hall. (1986). Career development in organizations. In Hall, D. T., \& Associates (Eds.). San Francisco: Jossey-Bass Inc.

[17] Jumpstart Coalition for Personal Financial Literacy. (2007). National standards in K-12 personal finance education (3rd ed.). Washington D.C.: Jumpstart Coalition. Retrieved from http://www.jumpstartcoalition.org

[18] Yamauchi, K. T., \& Templer, D. I. (1982). The development of a money attitude scale. Journal of Personality Assessment, 46(5), 522-528.

[19] Lin, K. Y. (2014). To develop technological talents with the competency of integrating theory and practice through interdisciplinary STEM education. STEM-Oriented Technology Education, 1(1), 1-71.

[20] National Research Council. (2010). Exploring the Intersection of Science Education and 2lst Century Washington, D. C.: National Academies Press.

[21] Annette, S. (2001). The Story Factor: Inspiration, Influence and Persuasion through the Art of Storytelling. Cambridge, MA: Perseus Publishing.

[22] Basalyga, S. (2003). Student interest in engineering is on decline. Daily Journal of Commerce. Retrieved from http://djcoregon.com/news/2003/06/11/student-interest-in-engineering-is-on-decline

[23] Leung, S. M. (2005). Career and life planning: Trans-theoretical assumptions and strategies. Asian Journal of Counselling, 12(1), 79-93.

[24] Wang, S. N., Wu, T. K., \& Meng, Y. R. (2014). Study on the effects of using multimedia annotations to assist on-line reading comprehension for students with low reading abilities. Journal of Liberal Arts and Social Sciences, 10(4), 333-352.

[25] Alaba, S. O. (2007). The use of educational cartoons and comics in enhancing creativity in primary school pupils inIle-ife, Osun State, Nigeria. Journal of Applied Sciences Research, 3(10), 913-920.

[26] Chen, S. C., Liu, F. M., \& Tseng, W. C. (2014). Education of older adults and multimedia applications - the impact of internal, external factors and innovative behavior on the effectiveness of teaching and learning. Journal of Gerontechnology and Service Management, 2(2), 153-170.

[27] Tang, T. L. P. (1995). The development of a short money ethic scale: Attitudes toward money and pay satisfaction revisited. Personality and Individual Differences, 19(6), 809-816.

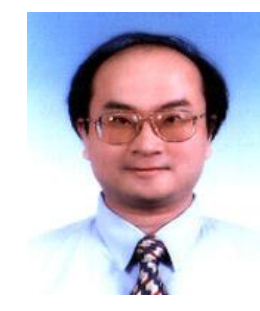

image processing.

Ting Sheng Weng is an associate professor of the Department of Business Administration at National Chiayi University, Taiwan. He received his Ph. D. in division of management and information science, Graduate School of Advanced Technology from Kinki University, Japan in 2000. He had served as visiting professor at Meiji University in Japan from 2006 through 2007. His major research interests include science technology and management, e-learning, information education, technology education, animations and comics, MIS, and 